\title{
Dispositional Optimism and Treatment Compliance in Heroin Addicts
}

\author{
Uzma Zaidi $^{1}$ \\ ${ }^{I}$ (Associate Professor, Clinical Psychology Track, Department of Health, College of Health and Rehabilitation, \\ Princess Nourah Bint Abdulrahman University, Riyadh, Kingdom of Saudi Arabia)
}

\begin{abstract}
The current study aimed to investigate the relationship of dispositional optimism and treatment compliance in heroin addicts. It was hypothesized that dispositional optimism would be negatively correlated with treatment compliance in them. Seventy Heroin addicts with an age range of 18 to 40 years were selected through purposive sampling from addiction rehabilitation centers and hospitals of Lahore, Pakistan. Life Orientation Test-Revised assessed dispositional optimism and Treatment Motivation Questionnaire assessed treatment compliance, were administered. Pearson Correlation and Linear Regression Analysis suggested that there is a significant negative correlation between the dispositional optimism and treatment compliance in heroin addicts. Signification relation was found between treatment compliance and variables of External reason, Internal reason, help seeking and confidence. Additionally, correlation of number of relapses with dispositional optimism and treatment compliance was done. Result can be demonstrated to psychiatric and nonpsychiatric population and therapeutic intervention should be applied to overcome these problems.
\end{abstract}

Keywords: dispositional optimism, heroin addicts, relapses, treatment compliance, treatment motivation

\section{Introduction}

Drug addicts become physically and emotionally dependent on chemical substances (narcotics or alcohol) that impair their physical, emotional, social and even vocational functions. ${ }^{[1]}$ The issue of drug addiction is often compounded by social problems, such as illiteracy, poverty and lack of basic health care. The term addiction derived from the Latin word addicere, "to sentence" ${ }^{[2]}$ and is a pattern of compulsive use of psychoactive substances to the point where drug use interferes with one's normal activities in life ${ }^{[3]}$, and identify three stages of the process. The first involves internal changes where personality begins to alter as a result of the intoxicating experiences. The second stage involves changes in lifestyle. The final stage starts when the addict goes out of control. Addiction is a pattern of substance use, leading to clinically significant impairment or distress as manifested by three (or more) of the following, occurring anytime in a 12-month period. Chemical substance is regularly taken in large amounts or for longer periods than intended; Persistent desire or unsuccessful efforts to cut down or control substance use; A great deal of time is spent in activities necessary to obtain the substance such as visiting multiple doctors or driving long distances or use of the substance (chain smoking), or to recover from its effects; Important social, occupational or recreational activities are given up or reduced because of substance abuse and continued substance abuse despite knowledge of having persistent or recurrent psychological or physical problems that are caused or exacerbated by abuse of the substance. ${ }^{[4]}$

Optimism is assessed and conceptualized in a variety of ways, has been linked to positive mood and good morale; to perseverance and effective problem solving; to academic, athletic, military, occupational, and political success; to popularity; to good health; and even to long life and freedom from trauma. ${ }^{[5]}$ Taylor ${ }^{[6]}$ presented three different ways in which people see themselves in more positive way or other people's views of the situations. First, they saw past behavior, personal attributes and self in an enhanced light. Second, they have unrealistic sense of personal control and unfounded belief that they can do better. Third, they have the unfounded sense of optimism in which they had a belief of having the opportunity for good things than adversity, stress and chaos.

Two main approaches to the measurement of the optimism these are based on distinct conceptualization of optimism ${ }^{[7]}$ and include dispositional optimism and optimistic explanatory style. ${ }^{[8]}$ Dispositional optimism is a global expectation that more good things than bad will happen in the future. Whereas utilizing optimistic explanatory style, people in the face of difficulties, continue to pursue their valued goal and regulate themselves and their personal states using effective coping strategies so that they are likely to achieve their goals ${ }^{[9]}$. Scheier and Carver, argued that, positive expectations are usually combined with (reverse-scored) negative expectations, and the resulting measure is investigated with respect to health, happiness, and coping with adversity ${ }^{[8.9]}$.

Another concept of positive illusions is closely related with dispositional optimism. This positive illusion basically serves as a coping strategy for drug addicts. Drug used persons used positive illusions to 
balance their sexual and aggressive impulses with their need to behave in a socially acceptable way. These are: self-deception, denial and repression, selective attention and benign forgetting, pockets of incompetence, and negative self - schema ${ }^{[10]}$.

Nezlek and Zebrowski ${ }^{[11]}$ examined dimensions of unrealistic optimism which were comprised of problems in specific domains, sexuality, substance abuse, and mental health. They identified that participants' dispositional optimism and psychological well-being were negatively correlated with perceived risk of experiencing mental health problems, whereas these measures were unrelated to perceived risks for other types of problems. According to Correa, Pasco, Leon, and Jareno ${ }^{[12]}$, pessimism is positively related with the report of physical symptoms, whereas optimism is negatively associated to somatic complaints; and this relationship can be mainly explained by the differential utilization of the coping strategy denominated self-criticism. Ayub ${ }^{[13]}$ found hopelessness is one of the most common predictor of suicide ideation.

At one end if dispositional optimism related to thinking patterns and coping strategies, some researches ${ }^{[14],[15]}$ found that treatment compliance is directly related to behavior that promotes or create resistance in drug addicts while getting treatment.

Treatment compliance is the variable that is intrinsic in nature and its diversity influence the treatment. It is considered as the degree to which a patient follow his/her assigned treatment regimen. Treatment compliance is known as adherence, a degree to which a patient carries out the clinical recommendations of the treating physician. Examples of compliance include keeping appointments, entering in and completing course of treatment program, taking medications correctly, and following recommended changes in behavior or diet. Thus treatment compliance behavior depends on the specific clinical situation, the nature of the illness, and the treatment program. Compliance is the degree of concurrence between the client's behaviors (such as taking medicine, sticking to a diet, changing lifestyle). Compliance can be increased if the physician explains the value to the patient of a particular treatment outcome and explains that following recommendations will produce that outcome. Compliance can also increase if the patients know the names and effects of each drug they are taking $^{[16]}$. Compliance is also found having correlation with socio-demographic and treatment variables of drug addicts ${ }^{[17]}$. Treatment compliance is also known as treatment motivation. It is comprised of four components i.e. external motivation, internal motivation, help seeking and confidence ${ }^{[18]}$.

Self-Determination Theory developed by Deci and $\operatorname{Ryan}^{[18]}$ represents a wide framework for the study of human inspiration and personality. SDT articulate a meta-theory for framing motivational studies that defines intrinsic and varied extrinsic sources of motivation, and a description of the respective roles of intrinsic and types of extrinsic motivation in cognitive and social development and in individual differences. The SDT framework therefore has both wide and behavior-specific implications for understanding practices and structures that enhance versus diminish need satisfaction and the full functioning that follows from it. Ryan, Plant, and $\mathrm{O}^{\prime}$ Malley ${ }^{[19]}$ concluded that internalized motivation was associated with greater patient involvement and retention in treatment. External motivation changed (decreased), whereas the other dimensions of motivation retained the high levels observed pretreatment ${ }^{[20]}$. In Pakistan, a research ${ }^{[21]}$ found that problem of poor compliance may be overcome with simple health messages even when the majority of individuals are illiterate and without formal education.

\section{Objectives}

Most of the treatment providers complain that drug addicts do not respond to the treatment properly. Treatment outcomes based on various phenomena. It may include personal, psychological, social and environmental factors. People's perceptions, expectations as well as motivations may play a vital role in adherence or compliance toward treatment. Optimism usually positively relates with different physical and psychological treatment programs. While studies conducted on drug users yield very unique findings. Those drug users who have optimistic views show lack of motivation to get treatment ${ }^{[22]}$. They often appear to be contented with their present condition. There were many studies related to personality traits ${ }^{[23]}$ (Vukov, Mikic, Lecic, Mijalkovic, \& Marinkovic, 2007), social support ${ }^{[23],[24]}$ (Olfson et al., 2000; Zaidi, 2007) Neuropsychological correlates ${ }^{[25]}$ (Zaidi, Afzal \& Amin, 2012) and socio- demographic correlates of drug addicts (Riaz \& Zaidi, 2007). So this study was designed to find out the perceptions, cognitive patterns and behaviors of drug addicts that involves in treatment process. There is a dearth of literature on the association of dispositional optimism and treatment compliance especially in Pakistan, therefore study will serve to fulfill the gap. The basic aim and objective of current study is to investigate whether dispositional optimism is significantly correlated with treatment compliance in drug addicts.

\section{Hypotheses}

\section{It was hypothesized that}

1. Dispositional optimism would have significant negative correlation with treatment compliance in heroin addicts. 
2.Treatment compliance would have significant positive correlation with external reasons, internalized reasons, help seeking and confidence in heroin addicts.

Additionally it was also hypothesized that, Dispositional Optimism, treatment compliance would have significant correlation with number of relapses in heroin addicts.

\subsection{Participants}

\section{Methodology}

Sample of the study included seventy male heroin addicts from different drug treatment centers of Lahore i.e. Fountain House, Punjab Institute of Mental Health and psychiatry departments of various hospitals through purposive sampling technique. The participants were male. The age range was 18 to 40 years $(\mathrm{M}=$ 27.07, $\mathrm{SD}=6.02$ ) with minimum education of primary. Drug addicts must be dependent /abuser of heroin ${ }^{[4]}$. Those drug addicts who were on other type of drugs than heroin were excluded. The alcoholic dependents/abusers were also excluded. Table (1) indicates that most of the heroin addicts' age range was 18-25 years. Data show that majority of the participants had done middle school (35\% drug addicts) and did matriculation (35\% drug addicts). Treatment variable shows that majority (51.4\%) were drug addicts from less than five years and experience relapse (35.7\%) one time. Demographics also indicate that (51\%) addicts were married and a majority $(90 \%)$ addicts belonged to low socioeconomic status.

Table 1 Descriptive statistics of variables $(N=70)$

\begin{tabular}{|c|c|c|c|}
\hline Characteristics & Frequency & Percentage & \\
\hline \multicolumn{4}{|l|}{ (1) Age } \\
\hline $18-25$ years & 31 & & $44.3 \%$ \\
\hline $26-30$ years & 19 & & $27.1 \%$ \\
\hline $31-35$ years & 12 & & $17.1 \%$ \\
\hline $36-40$ years & 8 & & $11.4 \%$ \\
\hline \multicolumn{4}{|l|}{ (2) Education of Drug addicts } \\
\hline Middle & 25 & & $35.7 \%$ \\
\hline Matriculation & 25 & & $35.7 \%$ \\
\hline Intermediate & 14 & & $20.0 \%$ \\
\hline Graduate & 6 & & $8.6 \%$ \\
\hline \multicolumn{4}{|l|}{ (Table 1 Continue...) } \\
\hline \multicolumn{4}{|l|}{ (3) Duration of Drug Addiction } \\
\hline $1-5$ years & 36 & & $51.4 \%$ \\
\hline $6-10$ years & 18 & & $25.71 \%$ \\
\hline $11-15$ years & 12 & & $17.1 \%$ \\
\hline $16-20$ years & 2 & & $2.8 \%$ \\
\hline $21-25$ years & 0 & & 0 \\
\hline More than 25 years & 2 & & $2.8 \%$ \\
\hline \multicolumn{4}{|l|}{ (4) Number of Relapses } \\
\hline 1 time & 25 & & $35.7 \%$ \\
\hline 2 times & 21 & & $30 \%$ \\
\hline 3 times & 9 & & $12.8 \%$ \\
\hline 4 times & 5 & & $7.1 \%$ \\
\hline 5 times & 6 & & $8.5 \%$ \\
\hline 6-10 times & 4 & & $5.7 \%$ \\
\hline \multicolumn{4}{|l|}{ (5) Marital Status } \\
\hline Married & 36 & $51.4 \%$ & \\
\hline Unmarried & 34 & & $48.6 \%$ \\
\hline \multicolumn{4}{|l|}{ (6) Socioeconomic status } \\
\hline Low & 63 & & $90.0 \%$ \\
\hline Middle & 3 & $4.3 \%$ & \\
\hline High & 4 & $5.7 \%$ & \\
\hline
\end{tabular}

4.2 Measures

Demographic data sheet, life Orientation Test-Revised ${ }^{[26]}$ and Treatment Motivation Questionnaire ${ }^{[27]}$ were used. 


\subsubsection{Demographic Information Form}

Demographic information form was used to obtain the demographic and other relevant information such as name, age, monthly income, type \& period of addiction, number of treatment, relapse and friends, birth order, education, and marital status about the heroin addicts.

\subsubsection{Life Orientation Test-Revised}

LOT $^{[26]}$ was designed to assess individual differences in generalized optimism verses pessimism. The test contains (10) items of five point Likert-type scale which ranges from strongly disagree (0) to strongly agree (3). There were reverse code items $(3,7$ and 9). Sum items $(1,3,4,7,9$, and 10) to obtain an overall score. High score imply optimism while low score are indicative of pessimism. There are items $(2,5,6$, and 8$)$ serves as filler items only. This measure has been used in a good compact of research on the behavioral, affective, and health consequences of this personality variable. Reliability of this test is $(0.95)$ high $^{[26]}$. The scale was translated after taking permission from author. Standard procedure of translation and back translation was adapted. Before achieving the main objectives of the study, reliability of the scales were calculated to check the homogeneity of the scale in Pakistani cultures. After translating the test into Urdu, reliability of the scale was calculated using chronbach alpha (that was 0.65 ). The Coefficient for scale is near the acceptance range, and this shows that the scale being employed in this study is reliable instrument for measurement of the constructs of interest.

\subsubsection{Treatment Motivation Questionnaire}

$\mathrm{TMQ}^{[27]}$ is a (26-item) self-report questionnaire designed to measure subjects' reasons for entering and remaining in substance abuse treatment. The TMQ was developed to factor analyses. Analyses describe the measure contains four identifiable factors: (a) internal Reasons (1, 2, 4, 5, 7, 8, 9, 11, 15, 20, 23); (b) external Reasons $(3,6,10,12)$; (c) help-seeking $(17,18,19,22,25,26)$ and (d) confidence in treatment $(13,16,21,24$ Reversed score and 14). Subjects rate every question based on a seven-point Likert scale (with 1 representing not at all true and 5 representing very much true). The scoring of the TMQ is that to calculate the four subscale scores by averaging the responses for item in that subscale and items reverse code before averaging. Higher scores is indicative of high treatment motivation.

TMQ correlates highly with clinician ratings of overall disturbance, overall motivation, identified motivation, introjected motivation, and external motivation. Assessment of internal reliability found Cronbach's alphas (ranging from .70 to .98$)^{[27]}$. The scale was translated after taking permission from author. Standard procedure of translation and back translation was adapted. Before achieving the main objectives of the study, reliability of the scales were calculated to check the homogeneity of the scale in Pakistani cultures. After translating the test into Urdu, reliability of the scale was calculated using Chronbach's alpha (that was 0.77). The Coefficient for scale is near the acceptance range, and this shows that the scale being employed in this study is reliable instrument for measurement of the constructs of interest.

\subsection{Procedure}

Permission from the concerned authority was sought for the purpose of data collection. After getting formal official permission, data collection was started. The data was collected from Fountain House, Punjab Institute of Mental Health and from psychiatry departments of various hospitals. The heads of the respective hospitals were requested for the data collection. Data was collected from the participants during the given time by heads. Prior to providing the questionnaires, the consent of each participant was obtained personally by providing them the consent form and the nature and purpose of the research study was also explained in detail to the participants. A demographic data sheet was used to gather the personal information about participants including their Age, education, marital status and number of relapses. Information related to their financial characteristics was taken through monthly income and socio-economic status. Some information related to family structure was also gathered i.e. Number of friends, siblings and their birth order. For information about their addiction the following data was gathered through demographic sheet; type, duration and quantity of addiction. A consent form was also given to the care takers of addicts. The questionnaires were administered by translating it into Urdu. After administration of Life Orientation Test-Revised ${ }^{[26]}$ and Treatment Motivation Questionnaire ${ }^{[27]}$ was administer after the break of 15 minutes.

\section{Results and Discussion}

Table 2 Relationship between Dispositional Optimism and Treatment Compliance in Drug Addicts Variable Treatment Compliance

Dispositional Optimism $\quad-0.28 *$

$* \mathrm{p}<0.05$ (two tailed) 
Table 3 Dispositional optimism as predictor of treatment compliance in heroin addicts

\begin{tabular}{cccccccc}
\hline $\begin{array}{c}\text { Outcome } \\
\text { variable }\end{array}$ & Predictor & $\mathbf{B}$ & SEB & $\square$ & $\mathbf{R}$ & $\mathbf{R}^{2}$ & $\Delta \mathbf{R}^{2}$ \\
\hline $\begin{array}{c}\text { Treatment } \\
\text { Compliance }\end{array}$ & $\begin{array}{c}\text { Dispositional } \\
\text { optimism }\end{array}$ & -1.271 & .529 & $-.019^{*}$ & .280 & .078 & .065 \\
\hline p $<0.05$ & & & & & & &
\end{tabular}

$* \mathrm{p}<0.05$

Table 4 Relationship between Dispositional Optimism and subscales of Treatment Compliance in Drug Addicts Variable Dispositional Optimism

$\begin{array}{ll}\text { External Reason } & -.78^{* *} \\ \text { Internalized reason } & -.86^{* *} \\ \text { Help Seeking } & -.72^{* *} \\ \text { Confidence } & -.47^{* *}\end{array}$

$\mathrm{p}<0.05$ (two tailed)

Table 5 Relationship between Dispositional Optimism, Treatment Compliance and number of relapses in Drug Addicts

Variable

Number of relapses

Dispositional Optimism $\quad .063$

Treatment Compliance $\quad-.26^{*}$

$* \mathrm{p}<0.05$ (two tailed)

SPSS (statistical package for social sciences) version 17.0 was used to analyze data. Descriptive statistics was used to calculate frequencies and percentages. The result indicated that there is a significant $[\mathrm{N}=$ $\left.70, r=-0.28^{*}, \mathrm{p}<.05\right]$ negative correlation between dispositional optimism and treatment compliance showing that greater the dispositional optimism, lower is treatment compliance in heroin addicts. The hypothesis has supported (Table 2).

Subsequently, linear regression analysis was conducted to assess whether dispositional optimism is determinant of treatment compliance in heroin addicts. Result (Table 3) indicates that $78 \%$ of dispositional optimism determines treatment compliance in heroin addicts. $\left[\mathrm{N}=70, \mathrm{R}^{2}=.078, \mathrm{p}<.05\right]$. Dispositional optimism serves as predictor that has an impact on outcome i.e. treatment compliance in heroin addicts. Furthermore, it was hypothesized that dispositional optimism and treatment compliance is significantly correlated with socio-demographic variables in heroin addicts. Pearson correlation was also used to see the relationship between treatment compliance and above mentioned four variables of treatment compliance (i.e., external reasons, internalized reasons, help seeking and confidence) (Table 4) The result indicated that there is a positive significant relationship between treatment compliance and external reasons [ $\left.\mathrm{N}=70, \mathrm{r}=.78^{* *}, \mathrm{p}<.05\right]$, treatment compliance and internalized reasons $\left[\mathrm{N}=70, \mathrm{r}=.86^{* *}, \mathrm{p}<.05\right]$, treatment compliance and help seeking $\left[\mathrm{N}=70, \mathrm{r}=.72^{* *}, \mathrm{p}<.05\right]$, and treatment compliance and confidence [ $\left.\mathrm{N}=70, \mathrm{r}=.47^{* *}, \mathrm{p}<.05\right]$, showing that higher the treatment compliance, higher will be the external reasons, internalized reasons, help seeking and confidence in treatment among heroin addicts. Further number of relapses $\left[\mathrm{N}=70, \mathrm{r}=-.26^{* *}, \mathrm{p}<.05\right]$ were inversely correlated with treatment compliance (Table 5).

The present study was conducted to investigate the relationship of dispositional optimism and treatment compliance in heroin addicts. It was hypothesized that dispositional optimism will be negatively correlated with treatment compliance in heroin addicts. The results indicate that there is significant negative relationship between dispositional optimism and treatment compliance in heroin addicts.

According to Downey, Rosengren, Jackson, and Donovan ${ }^{[28]}$ the heroin preference group reported less abstinence and lower treatment compliance in the heroin addiction. The authors note down the importance of investigating methods for increasing treatment entry rates for opiate users who desire drug-free treatment. A research was conducted ${ }^{[29]}$ for improving adherence in drug addicts and the effect of treatment compliance. Three groups were formed for the research: experimental groups (contingent as well as non-contingent) and control group. The results show that contingent group had significantly longer treatment retention and ingested significantly more doses of naltrexone than either control group. Voucher group can significantly increase adherence to naltrexone maintenance in recently detoxified opioid dependent individuals.

It was hypothesized that there would have significant positive correlation between treatment compliance and external reasons, internalized reasons, help seeking and confidence in heroin addicts. Results show that these findings are consistent with prior researches ${ }^{[30]}$. Drug addict's reasons for seeking treatment 
were also examined in relation to treatment compliance. Research suggests that treatment compliance correlated with internal and external reasons. Drug Addicts who rated any of these reasons as influential were more likely to enter and complete treatment. More research is desired, knowledge of clients' reasons for seeking treatment might be useful in treatment matching. Results shows internal reasons are significantly related with treatment compliance. Another research was conducted on the external and internalized reasons ${ }^{[31]}$. The finding suggests that drug abusers' motivation for entering treatment is quite unstable without the presence of a strong external force. Some of our subjects reported development difficulties as a reason for not entering treatment. They concluded that injection drug users who received income from employment were significantly less willing to enter treatment because, among other difficulties, treatment is time-consuming. Results confirm the relationship of two variables. There is a strong stigma associated with help seeking treatment in treatment compliance ${ }^{[32][33]}$. Studies that determine drug use other than the primary drug of abuse suggest that greater other drug use is associated with help-seeking when the primary drug of abuse is alcohol ${ }^{[34]^{[35]}}$. It was hypothesized that there would be significant relationship of confidence with treatment compliance in drug addicts. Results confirm the said relationship. According to the Ryan, Plant, and O'Malley ${ }^{[27]}$ the effective treatment compliance include included for factors external reasons, internalized reasons, help seeking and confidence in the treatment. According to them, these factors are highly correlated with high treatment compliance. According to Downey, Rosengren, Jackson, and Donovan ${ }^{[28]}$ the heroin preference group reported less abstinence and lower treatment compliance in the heroin addiction. There is a strong stigma associated with help seeking treatment in treatment compliance $^{[32],[33]}$.

Finally, the last hypothesis was partially proved as treatment compliance was found inversely correlated with number of relapses. In the light of this result if practitioners and professionals remain more focused upon increasing the motivation for the treatment among addicts they can reduce negativity and chances of relapse.

\section{Conclusion}

Results can be demonstrated to psychiatric and non-psychiatric population. Seminars and therapeutic intervention should be conducted to make the psychiatric population aware the problems of addiction and telling them strategies to overcome these problems. Treatment motivational interviews will be beneficial in this regard. More over Cognitive Behavioral $(\mathrm{CBT})^{[36]}$, Psychosocial interventions ${ }^{[37]}$ and Motivational Interviewing strategies will yield improvement to modify the dispositional optimism in drug addicts.

There are several limitations have been noted in the present research. Suggestions in the light of these limitations are given for future researchers. Sample size should be increased and must be recruited from couple of different hospitals so that the results can be generalized. Data must be collected from different cities and areas of Pakistan. Different drug addicts and poly substance abusers must be taken for making comparisons between them.

\section{Acknowledgements}

I am thankful to the authors for giving me permission to use the concerned scales for the purpose of data collection. I would like to thank the Heads of hospitals and Drug treatment centers who gave me permission to collect data from their hospitals. I am also grateful to patients who participated in this study.

\section{References}

[1]. G. P. O’Connor,. Merck Manual. 2009.Retrieved from: http://www.merck.com $/ \mathrm{mmhe} / \mathrm{sec} 25 / \mathrm{ch} 312 / \mathrm{ch} 312 \mathrm{a} . h \mathrm{tml}$

[2]. N. Carlson, Foundations of physiological psychology. 6 (Sydney: Pearson Education, 2005).

[3]. K.C. Berridge, and T. E. Robinson, What is the role of dopamine in reward: hedonic impact, reward learning, or incentive salience, Brain Research, 28(3), 1998, 309-369.

[4]. American Psychiatric Association. Diagnostic and statistical manual of mental disorders, text revision 4 ( Washington, D.C.: American Psychiatric Association, 2000).

[5]. J. E. Gillham, The science of optimism and hope: A research symposium. (Radnor, PA: Templeton Foundation Press, 2000)

[6]. S. E. Taylor, Positive illusion: creative self-deception and the healthy mind. In A. Carr (Ed.), Positive psychology the science of happiness and human strengths (New York: Brunner-Routledge, 2004). 29, 222-226.

[7]. C. Peterson, The future of optimism. America Psychological, 55, 2000, 44-55.

[8]. M. Scheier, and C. Carver, Optimism, coping and health: assessment and implications of generalized outcome expectancies. Health Psychology, 4, 1985, 219-247.

[9]. M. Scheier, C. Carvan, and M. Bridges, Optimism, pessimism and psychological well-being. In E. Chang (Ed.), Optimism and pessimism: theory, research and practice, (Washington, DC: American Psychological Association, 2000).

[10]. A. Carr, Positive psychology the science of happiness and human strengths. (New York: Brunner-Routledge, 2004).

[11]. J. B. Nezlek, and B. D. Zebrowski, Implications of the dimensionality of unrealistic optimism for the study of perceived health risks. Journal of Social and Clinical Psychology, 20(4), 2001, 521-537.

[12]. M. Correa, D. R. Pasco, G. Leon, and G. Jareno, Relationship between dispositional optimism/pessimism and stress coping strategies. Psicothema, 18(1), 2006, 66-72. 
[13]. N. Ayub, Measuring hopelessness and life orientation in pakistani adolescents. The Journal of Crisis Intervention and Suicide Prevention, 30(3), 2009,153-160.

[14]. D. L. Sackett, Introduction. Compliance with therapeutic regimens, (Johns Hopkins University Press: Baltimore, 1976). 1-6.

[15]. R. B. Haynes, Determinants of compliance: The disease and mechanics of treatment. Compliance in health care, (Johns Hopkins University Press, Baltimore, 1979). 49-62.

[16]. H. I. Kaplan, B. J. Sadock, and J. A. Grebb, Synopsis of psychiatry behavioral sciences clinical psychiatry. 7 (New York: Williams \& Wilkins, 1994).

[17]. Z. Riaz, and U. Zaidi, Non inject able user of heroin: patterns and demographic characteristics of addicted of low socio economic status in Karachi, Pakistan. Pakistan Journal of Clinical Psychology. 38 (2), 2007, 79-92.

[18]. E. L. Deci, and R. M. Ryan, The "what" and "why" of goal pursuits: Human needs and the self-determination of behavior. Psychological Inquiry, 11, 2000, 227-268.

[19]. R. M. Ryan, W. R. Plant, and S. O'Malley, Initial motivations for alcohol treatment: relations with patient characteristics, treatment involvement, and dropout. Addictive Behaviors, 20(3), 2000, 279-297.

[20]. A. M. Cahill, B. Aninoff, H. Hosig, K. Muller, and C. Pulliam, Motivation for treatment preceding and following a substance abuse program. Addictive Behaviors, 28, 2002, 67-79.

[21]. T. Leslie, A. M. Rab, H. Ahmadzai, N. Durrani, M. Fayaz, J. Kolaczinski and M. Rowland, Compliance with 14-day primaquine therapy for radical cure of vivax malaria a randomized placebo-controlled trial comparing unsupervised with supervised treatment. Transactions of the Royal Society of Tropical Medicine and Hygiene, 98 (3), 2004, 168-173.

[22]. U. Zaidi, Social support and personality features as risk factors in vulnerability to treatment rejection in heroin addicts. doctoral diss., Institute of Clinical Psychology, University of Karachi, Pakistan, 2007.

[23]. M. Vukov, N. B. Mikic, D. Lecic, S. Mijalkovic, and J. Marinkovic, Personality dimensions of opiate addicts, Acta Psychiatrica Scandinavica,. 19(1), 2007, 103-107.

[24]. M. Olfson, D. Mechanic, S. Hansell, C. Boyer, J. Walkup, and P. J. Weiden, Predicting medication noncompliance after hospital discharge among patients with schizophrenia. Psychiatric Services, 51(2), 2000, 216-222.

[25]. U. Zaidi, A. Afzal, and R. Amin, Impaired neuropsychological functioning of heroin addicts on NFI. Journal of Pakistan Psychological Association. 1(1-2), 2012, 29-41.

[26]. M. F. Scheier, C. S. Carver, and M.W. Bridges, Distinguishing optimism from neuroticism: a re-evaluation of the life oriented test. Journal of Personality and Social Psychology, 67, 1994, 1063-1078.

[27]. R. M. Ryan, R. W. Plant, and S. O'Malley, Initial motivation for alcohol treatment: Relations with patient characteristics, treatment involvement and dropout. Addictive behaviors, 20, 1995, 279-297.

[28]. L. Downey, B. D. Rosengren, R. T. Jackson', and M. D. Donovan, Primary heroin users drug-free treatment: An equation for success? Addictive Behaviors, 28(2), 2003, 339-346.

[29]. L. K. Preston, K.. Silverman, A. Umbricht, A. Dejesus, D. I. Montoya, and R.C. Schuster, Improvement in naltrexone treatment compliance with contingency management, Drug and alcohol Dependence, 54(2), 1999, 127-135.

[30]. A. J. Cunningham, C. L. Sobell, B. M. Sobell, and J. Gaskin, Alcohol and drug abusers' reasons for seeking treatment. Addictive Behaviors, 16(9), 2002, 691-696.

[31]. J. Kleyn, and E. S. Lake, Factors associated with willingness to enter drug treatment: Some implications for policy. AIDS \& Public Policy Journal, 5(3), 1990, 112-116.

[32]. J. A. Cunningham, L. C. Sobell, M. Sobell, and J. Gaskin, Alcohol and drug abusers' reasons for seeking treatment. Addictive Behaviors, 19, 1994, 691-696.

[33]. J. A. Cunningham, L. C. Sobell, M. B. Sobell, S. Agrawal, and T. Toneatto, Barriers to treatment: Why alcohol and drug abusers delay or never seek treatment. Addictive Behaviors, 18, 1993, 347-353.

[34]. A.F. Bannenberg, H. Raat, and H. N. Plomp, Demand for alcohol treatment by problem drinkers. J Substance Abuse Treatment, 9 , 1992, 59-62.

[35]. T.G. Brown, P. Seraganian, and J. Tremblay, Alcoholics also dependent on cocaine in treatment: Do they differ from "pure"alcoholics? Addictive Behaviors, 19,1994, 105-112.

[36]. W. S. Schaumburg, Drug addiction in Pakistan, 2004. Retrieved December 30, 2009, from www.yespakistan

[37]. C. Spooner, Causes and correlates of adolescent drug abuse and implications for treatment. Drug and Alcohal Review, 18(4), 2009, 453-475. 